\title{
Models based instruction: the Sport Education curriculum model and accruing physical activity
}

\author{
Colin G. Pennington, Ph.D. \\ Tarleton State University
}

Keywords: field experience, secondary methods, MVPA, SOFIT, SOPLAY

\begin{abstract}
Evidence suggests that physical activity patterns become habitual during childhood, and it is possible that activity patterns continue into adulthood. Unfortunately, traditional physical education practices have been called into question in regard to the amount of vigorous physical activity the class actually provides. Undergraduate physical education teacher education programs provide an opportune setting in which preservice teachers can be introduced to the demand of meeting these unique and challenging goals with less pressure than under the responsibility of teaching full-time without university support. One curriculum model believed to address the concern of facing physical education is Sport Education. The purpose of this study was to determine what impact preservice teachers had on students accruing the recommended levels of moderate to vigorous physical activity (MVPA) during their early field experience of an undergraduate secondary methods course while teaching within the Sport Education curriculum model. Participants were four preservice teachers assigned to teach sport education to middle school students during a secondary methods course field experience. Leeson were filmed and analyzed using a modified version of the System for Observing Fitness Instruction Time and the System for Observing Play and Leisure Activity in Youth. Calculation of overall student activity shows that students were sedentary for $45.19 \%$ of the lesson duration, walking for $38.00 \%$ of the lesson, and vigorously active for $16.81 \%$ of their respective lesson. The discussion section outlines possible reasons for these results, as well as suggestions for physical educators to increase MVPA during Sport Education.
\end{abstract}

\section{Introduction}

The purpose of this study was to determine what impact preservice teachers had on students accruing the recommended levels of moderate to vigorous physical activity (MVPA) during their early field experience of an undergraduate secondary methods course while teaching within the Sport Education curriculum model. Specifically, to describe (a) the intensity of the activity in which middle school students engaged, (b) the degree to which preservice teachers embed fitness content and knowledge in their lessons, and (c) the extent to which preservice teachers directly prompt students to engage in physical activity and model fitness activity within the context of this curriculum model known to be focused on personal and social responsibility.

Evidence suggests that physical activity patterns become habitual during childhood, and it is possible that activity patterns continue into adulthood (Dishman, Heath, \& Lee, 2018; McKenzie et 
al., 1995). Due to evidence of increasingly high levels of adult and childhood obesity in the United States, there has been renewed effort to identify the etiology of this epidemic (Nelson et al., 2011). While poor nutrition has emerged as one contributing cause, the increasing prevalence of a sedentary lifestyle is also a major factor (Talarico \& Janssen, 2018), as regular physical activity has been shown to reduce one's likelihood of becoming obese and reducing heart disease (Moholdt, Lavie, \& Nauman, 2018). Recent Physical Activity Guidelines for Americans recommend that children and adolescents engage in at least 60 minutes of physical activity daily at the moderate to vigorous intensity levels (U.S. Department of Health and Human Services [USDHS], 2010). Unfortunately, traditional physical education practices have been called into question in regard to the amount of vigorous physical activity the class actually provides. Research shows that when teaching in models outside of health-related fitness, physical educators tend to use few behaviors aimed at prompting or promoting fitness (Curtner-Smith, Sofo, Chouinard \& Wallace, 2007). Therefore, it is possible that traditional Multi-Activity physical education curricula are deficient in providing the kinds of robust physical activity needed to combat these sedentary behavior trends (Nelson \& Wilson, 2011). In this light, scholars and professional organizations have called for innovative and well-designed physical education activities that achieve health-enhancing fitness (Physical Activity Guidelines Advisory Committee, 2008).

Physical educators are also called upon to meet the social development demands of their students (Hellison, 2009). Participation in physical education can help young people learn about themselves, handle adversity, and experience teamwork and sportsmanship (Rasmussen, 2000; Pennington, 2017). There is an opportunity to address these certain prosocial skills thought to develop in the grade school years (Pennington \& Sinelnikov, 2018), which is a time when children begin developing the necessary social skills to be successful and productive in society (Catalano et al., 2003). There is a growing body of evidence showing that children who achieve social competence during their formative years in education will become more successful and healthy throughout their lives (Pennington, 2019). The challenge for physical educators is to develop curriculums which address the need for accruing high levels of MVPA, and simultaneously create an atmosphere of student social development all while addressing the major educational outcome of developing skillful movers. Undergraduate physical education teacher education (PETE) programs provide an opportune setting in which preservice teachers can be introduced to the demand of meeting these unique and challenging goals with less pressure than under the responsibility of teaching full-time without university support. These are tall orders for beginning teachers and preservice teachers. All the more reason to expose preservice teachers to this challenge under more "controlled" teaching environments like that of field experiences supervised by the course professor, possibly graduate assistants, and/or the cooperating teacher of the field experience site.

\section{Overview of Sport Education}

One curriculum model believed to address the concern of personal and social development is Sport Education (Siedentop, Hastie \& Van der Mars, 2011), which provides a physically and emotionally safe environment where both high and low-skilled students can succeed. This is accomplished through integrating cooperative small-group work and peer teaching within activity settings, rather than total reliance on teacher-directed instruction. Sport Education has several unique features that distinguish it from other pedagogical models. A unit of Sport Education is organized into a season, lasting for at least 15-20 lessons, mimicking the flow of a regular sport season (i.e., training camp, preseason, regular season, post season). Students build affiliation by being members of the same team throughout the season as they plan, practice, and compete as a team. Much of the positive social meaning and personal growth derived from sport experiences is 
related to team affiliation. By engaging in formal competition, students have the opportunity to plan, strategize, and practice in the pursuit of team goals. Festivity is a key component of Sport Education as teachers and students work together to create an environment that celebrates improvement, effort, and fair play (e.g., posters hung on walls, team uniforms, player introductions before games, award ceremonies at the end of the season). Record keeping provides feedback for individuals and groups, helps to define performance standards (e.g. establishing benchmarks for fair play points over a game/season or goals/points, etcetera) and is fundamental to defining future goals. Finally, culminating events, such as festivity at the end of the season, create the opportunity for celebration of accomplishments.

A large body of research reflects an overall positive impact of Sport Education on teachers and students (Stran \& Curtner-Smith, 2009; Curtner-Smith \& Sofo, 2004; Wallhead \& O'Sullivan, 2005). This research indicates that students' cooperation level and ability to handle the challenges of developing proper social practices improves during Sport Education units (Parker \& CurtnerSmith, 2005). However, few studies have examined how preservice teachers employ the model, and the few studies available suggest preservice teachers have difficulties when first attempting to teach within Sport Education (Curtner-Smith \& Sofo, 2004; Parker \& Curtner-Smith, 2005; McMahon \& MacPhail, 2007), or even produced an environment counter to the positive sporting goals of Sport Education (Parker \& Curtner-Smith, 2012).

Sport Education's Link to MVPA. To date, research examining Sport Education has largely focused on gains in sporting performance or social development. Few studies have examined the effects of the model on students' health-related fitness. Hastie and Trost (2002) found that seventh grade boys who engaged in a 22-lesson Sport Education unit of floor hockey were in MVPA for just over $60 \%$ of the lesson. This level of MVPA generally exceeded levels reached in studies of traditional Multi-Activity teaching (e.g. Curtner-Smith, Chen \& Kerr, 1995; Curtner-Smith, Kerr \& Clapp, 1996). However, Parker and Curtner-Smith (2005) compared the health-related fitness benefits of students participating in Sport Education and Multi-Activity units of instruction, finding that students in the Multi-Activity unit spent slightly more than the recommended $50 \%$ of lesson time in MVPA while those in the Sport Education unit did not approach this level. Some suggest - if achieving high levels of MVPA is a teacher's priority - that MVPA accrual can be enhanced during a Sport Education unit by combining Sport Education with elements of Multi-Activity units (Parker \& Curtner-Smith, 2005). This suggestion is expanded on in the discussion of this article. There is a still a lack of research which provides evidence that preservice teachers are capable of delivering quality Sport Education while also contributing to the acquisition of recommended levels of MVPA.

\section{Method}

The preservice teachers in this study were four male Caucasian undergraduates enrolled in a seven-week secondary methods course field experience at a large public university situated in the southeastern United States. The unit preservice teachers were instructed to partner-teach was soccer. This was the first teaching opportunity within the context of their undergraduate training for any of the preservice teachers. Middle school participants were a mix of Caucasian and African-American students from a blend of low and middle-income families. Preservice teachers partner-taught one 12-lesson Sport Education soccer season to mixed-gender classes of 5-8 students. Responsibilities for teaching the class were shared equally between the partner preservice teachers. Lesson length was 60 minutes. At least one ball was available for each student, as was other essential equipment including cones to mark practice and playing areas for each group. The Sport Education season was divided into three phases. Phase 1 consisted of five lessons and was devoted to skill and strategy acquisition, learning roles, and team bonding. Phase 2 involved three lessons of preseason 
competition. Phase 3 consisted of four lessons where students participated in a five-game regular season, playoffs, and an awards ceremony. Skill drills, practices, small-sided games, and conditioned games used in the field experience were taken from the text Progressive Soccer Coaching: From Novice to Expert (Curtner-Smith, Johnson, \& Vincent, 2003). All participants signed consent forms in compliance with the university's human subjects policy and the field experience was supervised by the course professor and six doctoral students serving as mentors for the preservice teachers.

\section{Data Collection}

One Sport Education lesson taught by each of the preservice teachers during Phase 2 (the first lesson in Phase 2) was filmed using a Panasonic AG-450 video camera and a wireless microphone (NO: 32-1226). These lessons were purposefully selected because they occurred at a point in the field experience where preservice teachers and students had begun to form relationships and trust, and lessons primarily focused on small-sided activities and game-like drills where students each had one ball or shared a ball between pairs, thus increasing physical activity participation opportunities and preservice teachers' opportunities to provide focused feedback to students. Coding different lessons across the unit would likely yield different results, as lessons early in a unit, when taught by a novice or learning instructor, often requires ample amount of time devoted to verbal explanations and demonstrations (reducing physical activity opportunity), and lessons in which game-play is occurring may have flawed results because in Sport Education, some students are designated referees or statisticians - not game players- thus limiting their MVPA opportunity. Therefore, coding lessons at this point in the unit provided the most accurate data possible to capture physical activity patterns of students. Naturally, coding multiple or all lessons in an entire unit is the only way to definitively capture the physical activity patterns of a unit, but because of challenges related to time and resource allocation, only four lessons - deemed the best representation of physical activity patterns of the unit - were coded for in the present study.

Lessons were coded by a trained user of systematic observation instruments using a modified version of the System for Observing Fitness Instruction Time (SOFIT) instrument (McKenzie, Sallis \& Nader, 1991) and the System for Observing Play and Leisure Activity in Youth (SOPLAY; McKenzie, 2002). The two observation instruments were modified to be combined into one analysis instrument because of the uniqueness of teacher activity during a typical lesson of Sport Education (see Appendix). During a lesson of properly executed Sport Education, the teacher is "off stage" (Curtner-Smith, 2012), and the students are given the responsibilities of the teacher (i.e. warm-up leader, coach, referee, statistician). Therefore, the traditional version of SOFIT and SOPLAY were not appropriate for accurately capturing the events of the lessons or properly judging the behaviors of the teacher and students- although, the modified instrument used in this study closely resembles the traditional SOFIT instrument. Reasons for selecting SOFIT and SOPLAY to measure the MVPA of lessons are: (1) the financial cost of securing sophisticated digital equipment for multiple participants, and (2) to introduce practitioners who may not be familiar with these observation instruments with a cheap and straight-forward field-based method for evaluating the MVPA of their students and lessons. Four students, one from each preservice teacher's team, were deliberately selected for coding because they were game-play participants - not referees or statisticians.

Instrument. SOPLAY is based on momentary time sampling techniques in which systematic and periodic scans of individuals and contextual factors are made (McKenzie, 2002). During a scan, the activity of each individual is coded as sedentary (lying down, sitting, or standing), walking, or vigorously active. Similarly, SOFIT is a momentary time sampling and 
interval recording system designed specifically to quantify factors believed to promote healthrelated physical activity (McKenzie, Sallis \& Nader, 1991) enabling researchers and practitioners to make judgments about the effectiveness of lessons as they relate to physical activity goals. It is a tool that provides for the simultaneous collection of data on student activity levels, the lesson context, and teacher behavior. Coding with SOFIT is split into three phases. The first phase involves the observation and coding of students' physical activity levels. In this study, students' activity level was coded as sedentary, walking, or vigorous. The second coding phase involves the context of the lesson. Lesson context codes were planned presentation (i.e. teacher giving instruction, explaining rules, strategies, etc.) or game play (i.e. students participating in a smallsided soccer game). Traditionally SOFIT involves coding lesson closings. However, in this study, these data were not collected during lesson closings for individual teachers. The reason being all closings were conducted by the course professor - not the preservice teachers. The third phase traditionally involves coding for the teacher's behaviors. However, this data were not coded for, because during a lesson of properly executed Sport Education the teacher is "off stage" while the students carryout the responsibilities of the teacher. Instead, in this study, the final coding phase involved the SOPLAY concept of coding student behavior as being either on-task (i.e. student is participating in activity) or off-task (i.e. student is sedentary).

Data was collected for each lesson in the study by one coder. As per the SOFIT training manual (McKenzie, 2012), the physical activity levels of four students (one per each preservice teacher's lesson) were observed during the duration of the lesson, the lesson contexts in which they occurred, and student behaviors. These three elements were coded every ten seconds using momentary time sampling as per the standard SOPLAY and SOFIT protocols (McKenzie, 2012). Raw scores measured by the instrument for each preservice teacher's lesson context was measured and converted into percentages as was student activity level. Mean scores for overall lesson context and overall averages student activity level were computed.

\section{Results}

Table 1 illustrates the overall averages of student physical activity observed across all lessons contexts.

Table 1. The Percentage of Student Activity per Lesson Context, PT, and Overall

$\begin{array}{lllll}\text { PT 1 } & 27.00 & 68.00 & 32.00 & 0.00 \\ \text { PT 2 } & 31.00 & 56.00 & 44.00 & 0.00 \\ \text { PT 3 } & 40.00 & 71.00 & 29.00 & 0.00 \\ \text { PT 4 } & 40.00 & 88.00 & 12.00 & 0.00 \\ \text { Average } & 34.50 & 70.75 & 29.25 & 0.00 \\ & & & & \\ \text { PT 1 } & \text { Game Play \% } & \text { Sedentary } & \text { Walking } & \text { Vigorous } \\ \text { PT 2 } & 73.00 & 17.00 & 50.00 & 33.00 \\ \text { PT 3 } & 69.00 & 31.00 & 39.00 & 30.00 \\ \text { PT 4 } & 60.00 & 21.50 & 57.00 & 21.50 \\ \text { Average } & 60.00 & 9.00 & 41.00 & 50.00 \\ & 65.50 & 19.63 & 46.75 & 33.63\end{array}$


Sedentary

45.19
Walking

38.00
Vigorous

16.81

Note. $\mathrm{PT}=$ preservice teacher

Calculation of overall student activity shows that students were sedentary for $45.19 \%$ of the lesson duration, walking for $38.00 \%$ of the lesson, and vigorously active for $16.81 \%$ of their respective lesson. When students were engaged in game play, students were most frequently coded as walking (46.75\%), followed by vigorously active (33.63\%), and sedentary (19.63\%). During planned presentation, students were coded sedentary (70.75\%), walking (29.25\%), and never vigorously active $(0.00 \%)$. On average, preservice teachers spent $34.50 \%$ of the total lesson time in planned presentation and $65.50 \%$ of the lesson in actual game play.

During all phases of the lessons, the subject of health-related fitness was absent from each preservice teachers' direct discussion, instruction, or teaching. No opportunity was made by any preservice teacher to provide fitness content and fitness knowledge to their students. However, each preservice teacher was an active observer of game play, actively monitored students, and showed enthusiasm towards participation during the duration of the lesson - subjectively speaking; they were fine teachers for their level of teaching experience.

\section{Discussion}

Overall, preservice teachers in this study were not able to achieve the USDHS recommended levels of MVPA within the context of the observed Sport Education lesson. This is likely the result of a large amount of lesson time devoted to planned presentation. The large amount of time spent in planned presentation can be attributed to preservice teachers having little experience in the field, or wanting to demonstrate to their students and/or course professor their instructional ability but overexplaining in the process; they were therefore unable to deliver concise instruction using as little time necessary - this would likely be true during execution of any curriculum model for preservice teachers. All four preservice teachers appeared to be intent on providing thorough and accurate instruction as they were aware their teaching was being evaluated by their course professor or mentor. This was also a likely contributor to such a large percentage of their lessons being dedicated to planned presentation. For the middle school students, a large lesson percentage spent in planned presentation provides less opportunity to increase their MVPA as they are often stuck, standing in place, listening to instruction rather than being active.

Naturally, preservice teachers would not be expected to achieve as high a level of MVPA compared to experienced teachers. This can be attributed to either a lack of content knowledge, inability to effectively manage student behavior, having too strong of focus on their own tasks, or a combination of reasons (Parker \& Curtner-Smith, 2012). Still, little is known about the ability of preservice teachers to provide health-enhancing amounts of MVPA, fitness content and knowledge, and to prompt and model fitness when employing models that are not specifically aimed at healthrelated fitness. The findings of this study suggest the subject of health-related fitness, and achieving a high level of MVPA using Sport Education may not be expressed as a priority for preservice teachers during their university course work. While the evidence suggests Sport Education is certainly a model with many social benefits, it is not the ideal model when high MVPA is the main lesson objective.

Teachers often have little time to allocate towards improving fitness during the Sport Education unit outside of units deliberately designated towards the theme. The high volume of material to cover with little time means that peripheral subject matter, like that of health-related fitness, is often sacrificed as part of a trade-off (Hastie \& Curtner-Smith, 2006; Parker \& CurtnerSmith, 2005). Some of the characteristics which make Sport Education successful at improving 
prosocial behavior detract from opportunities to achieve high MVPA. Taking on roles such as statistician, scorekeeper, attending to administrative tasks, and taking part in a season-ending awards ceremony, for example, must mean that students are denied potential opportunities to participate in MVPA (Parker \& Curtner-Smith, 2005) - opportunities they might be given in MultiActivity units.

\section{Increasing MVPA Using Sport Education}

For preservice teachers to accrue high levels of MVPA while delivering authentic Sport Education, preservice teachers effectiveness could be strengthened by (1) limiting time spent in planned presentation, (2) incorporate health-related fitness discussions during planned presentation and closings (3), decrease the amount of time between transitions to new activities, (4) encourage faster pace of students during transitions and game play, (5) select sports known to involve more movement opportunity (i.e. soccer instead of softball), (6) utilize small-sided games throughout the season, and most importantly (7) receive more training from PETE instructors on how to teach for health-related fitness and adequately address the need for MVPA. Furthermore, coding with SOFIT/SOPLAY can inform preservice teachers and teachers to what degree their classrooms are engaged in physical activity, and illuminate specific lesson areas where the bulk of MVPA is occurring.

Furthermore, combining Sport Education with other curricular models has shown benefits of providing sporting experiences and allowing students to learn how to play well (Hastie \& CurtnerSmith, 2006; Harvey, Smith, Fairclough, Savory \& Kerr, 2015). A final recommendation is for physical educators, PETE instructors, and preservice teachers to consider preceding a Sport Education season with a Multi-Activity unit during field experience training to optimize the inherent benefits each model has to offer. The Sport Education and Multi-Activity models complement one another well, as students learn and train to master the skills of a given sport within the Multi-Activity unit, and then develop positive social practices while performing those skills within the context of their Sport Education season. Traditional Multi-Activity offers the advantage of direct teaching styles to teach the skills of a sport preceding the Sport Education season and provide many opportunities to accrue MVPA. Trends in data suggest students are more likely to learn directly about health and fitness in Multi-Activity units compared to Sport Education units, alone (Parker \& Curtner-Smith, 2005). The results of the present study lends support to the belief that physical educators should choose multiple curricular models to meet both the sporting performance and/or prosocial development goals of their students, knowing that one model, alone, is inadequate to address both needs sufficiently.

\section{Contextualizing the Environment}

One challenge for educators is to accurately analyze the physical activity patterns of a class by looking at one lesson. One limitation of this study was that only one lesson was coded. This lesson was purposefully selected because it occurred at a point in the field experience where results would be a fair representation of the physical activity that occurs during the Sport Education season while all students were active participants, and preservice teachers had opportunities to provide psychomotor- and physical activity -based feedback to all students. For those interested in using SOFIT/SOPLAY to evaluate the physical activity patterns of students in a Sport Education season, contextualizing the phase of the season will provide depth of insight to the results. Lastly, student motivation to participate may be fluid throughout a Sport Education unit when student roles change. Fostering a positive sporting environment is crucial to increasing students' readiness and willingness to participate with enthusiasm and intensity (Pennington, 2018). Having a positive 
competitive climate suggests greater enjoyment in physical education and sport and intrinsic motivation, thus enhancing enthusiastic participation taking the form of enhanced MVPA.

\section{References}

[1] Catalano, R. F., Mazza, J. J., Harachi, T. W., Abbott, R. D., Haggerty, K. P., \& Fleming, C. B. (2003). Raising healthy children through enhancing social development in elementary school: Results after 1.5 years. Journal of School Psychology, 41(2), 143-164.

[2] Curtner-Smith, M. D., Chen, W. \& Kerr, I. G. (1995). Health-related fitness in secondary school physical education: a descriptive-analytic study, Educational Studies, 21(1), 55- 66.

[3] Curtner-Smith, M. D., Kerr, I. G. \& Clapp, A. J. (1996). The impact of national curriculum physical educate on the teaching of health-related fitness: a case study in one English town, European Journal of Physical Education, 1(1), 66- 83.

[4] Curtner-Smith, M.D., Johnson, M.L., \& Vincent, J. (2003). Progressive soccer coaching: From novice to expert (2nd ed). Boston, MA: American Press.

[5] Curtner-Smith, M., \& Sofo, S. (2004). Preservice teachers' conceptions of teaching within sport education and multi-activity units. Sport, Education and Society, 9(3), 347-377.

[6] Curtner-Smith, M., Sofo, S., Chouinard, J., \& Wallace, S. (2007). Health-promoting physical activity and extra-curricular sport. European Physical Education Review, 13(2), 131-144.

[7] Curtner-Smith, M. (2012). Preparing preservice physical education teachers to teach sport education. Sport education: International perspectives, 151-165.

[8] Dishman, R. K., Heath, G. W., \& Lee, I. M. (2018). Physical activity epidemiology. Human Kinetics.

[9] Harvey, S., Smith, L., Fairclough, S., Savory, L., \& Kerr, C. (2015). Investigation of Students' Levels of MVPA and VPA During Physical Education Units Focused on Direct Instruction and Tactical Games Models. Physical Educator, 72, 40-58.

[10] Hastie, P. A., \& Trost, S. G. (2002). Student physical activity levels during a season of sport education. Pediatric Exercise Science, 14(1), 64-74.

[11] Hastie, P. A., \& Curtner-Smith, M. D. (2006). Influence of a hybrid Sport Education-Teaching Games for Understanding unit on one teacher and his students. Physical Education \& Sport Pedagogy, 11(01), 1-27.

[12] Hellison, D. (2009). Engaging Urban Youths: A youth development perspective. Journal of Physical Education, Recreation \& Dance, 80(8), 27-34.

[13] McKenzie, T. L., Sallis, J. F., \& Nader, P. R. (1991). SOFIT: System for Observing Fitness Instruction Time. Journal of Teaching in Physical Education, 11, 195-205.

[14] McKenzie, T. L., Feldman, H., Woods, S. E., Romero, K. A., Dahlstrom, V., Stone, E. J., \& Harsha, D. W. (1995). Children's activity levels and lesson context during third-grade physical education. Research Quarterly for Exercise and Sport, 66(3), 184-193.

[15] McKenzie, T. L. (2002). System for observing play and leisure activity in youth (SOPLAY). Retrieved August, 1, 2006.

[16] McKenzie, T. L. (2012). SOFIT (System for Observing Fitness Instruction Time): Generic Description and Procedures Manual. San Diego, CA: San Diego State University.

[17] McMahon, E., \& MacPhail, A. (2007). Learning to teach sport education: The experiences of a pre-service teacher. European Physical Education Review, 13(2), 229-246.

[18] Moholdt, T., Lavie, C. J., \& Nauman, J. (2018). Sustained physical activity, not weight loss, associated with improved survival in coronary heart disease. Journal of the American College of Cardiology, 71(10), $1094-1101$.

[19] Nelson, L., Guess, W., Olson, T., Buckwalter, J., Evans, M., \& Morris, M. (2011). Heart rates of elementary physical education students during the dancing classrooms program. Research Quarterly for Exercise and Sport, 82(2), 256-263.

[20] Nelson, L. P., \& Wilson, A. (2011). Impact of Dancing Classrooms on elementary physical education: A school climate study of personal and social development. Texas Association for Health, Physical Education, Recreation, and Dance Journal, 78(3).

[21] Parker, M. B., \& Curtner-Smith, M. (2005). Health-related fitness in sport education and multi-activity teaching. Physical Education \& Sport Pedagogy, 10(1), 1-18.

[22] Parker, M. B., \& Curtner-Smith, M. D. (2012). Sport education: a panacea for hegemonic masculinity in physical education or more of the same?. Sport, Education and Society, 17(4), 479-496.

[23] Pennington, C. G. (2017). Moral Development and Sportsmanship in Physical Education and Sport. Journal of Physical Education, Recreation \& Dance, 88(9), 36-42. 
[24] Pennington, C. G. (2018). Creating and Confirming a Positive Sporting Climate. Journal of Physical

Education, Recreation \& Dance. Manuscript in print.

[25] Pennington, C. G. \& Sinelnikov, O. (2018). Using Sport Education to Promote Social Development in Physical Education. Strategies: Advocacy in Action. 34(6).

[26] Physical Activity Guidelines Advisory Committee. (2008). Physical activity guidelines advisory committee report, 2008. Washington, DC: US Department of Health and Human Services, 2008, A1-H14.

[27] Rasmussen, K. (2000). The Changing Sports Scene. Educational Leadership, 57(4), 26-29.

[28] Siedentop, D., Hastie, P. A., \& Van der Mars, H. (2011). Complete guide to sport education. Human Kinetics. [29] Stran, M., \& Curtner-Smith, M. D. (2009). Influence of two preservice teachers' value orientations on their interpretation and delivery of sport education. Sport, Education and Society, 14(3), 339-352.

[30] Talarico, R., \& Janssen, I. (2018). Compositional associations of time spent in sleep, sedentary behavior and physical activity with obesity measures in children. International Journal of Obesity, 1.

[31] U.S. Department of Health and Human Services. (2010). 2010 physical activity guidelines for Americans. Washington DC: Author. Retrieved from http://www.health.gov/PAGuidelines/guidelines/default.aspx\#toc.

[32] Wallhead, T., \& O'sullivan, M. (2005). Sport education: Physical education for the new millennium?. Physical Education and Sport Pedagogy, 10(2), 181-210. References

[33] Dishman, R. K., Heath, G. W., \& Lee, I. M. (2018). Physical activity epidemiology. Human Kinetics.

[34] McKenzie, T. L., Feldman, H., Woods, S. E., Romero, K. A., Dahlstrom, V., Stone, E. J., \& Harsha, D. W. (1995). Children's activity levels and lesson context during third-grade physical education. Research Quarterly for Exercise and Sport, 66(3), 184-193.

[35] Nelson, L., Guess, W., Olson, T., Buckwalter, J., Evans, M., \& Morris, M. (2011). Heart rates of elementary physical education students during the dancing classrooms program. Research Quarterly for Exercise and Sport, 82(2), 256-263.

[36] Talarico, R., \& Janssen, I. (2018). Compositional associations of time spent in sleep, sedentary behavior and physical activity with obesity measures in children. International Journal of Obesity, 1.

[37] Moholdt, T., Lavie, C. J., \& Nauman, J. (2018). Sustained physical activity, not weight loss, associated with improved survival in coronary heart disease. Journal of the American College of Cardiology, 71(10), 1094-1101.

[38] U.S. Department of Health and Human Services. (2010). 2010 physical activity guidelines for Americans. Washington DC: Author. Retrieved from http://www.health.gov/PAGuidelines/guidelines/default.aspx\#toc.

[39] Curtner-Smith, M., Sofo, S., Chouinard, J., \& Wallace, S. (2007). Health-promoting physical activity and extra-curricular sport. European Physical Education Review, 13(2), 131-144.

[40] Nelson, L. P., \& Wilson, A. (2011). Impact of Dancing Classrooms on elementary physical education: A school climate study of personal and social development. Texas Association for Health, Physical Education, Recreation, and Dance Journal, 78(3).

[41] Physical Activity Guidelines Advisory Committee. (2008). Physical activity guidelines advisory committee report, 2008. Washington, DC: US Department of Health and Human Services, 2008, A1-H14.

[42] Hellison, D. (2009). Engaging Urban Youths: A youth development perspective. Journal of Physical Education, Recreation \& Dance, 80(8), 27-34.

[43] Rasmussen, K. (2000). The Changing Sports Scene. Educational Leadership, 57(4), 26-29.

[44] Pennington, C. G. (2017). Moral Development and Sportsmanship in Physical Education and Sport. Journal of Physical Education, Recreation \& Dance, 88(9), 36-42.

[45] Pennington, C. G. \& Sinelnikov, O. (2018). Using Sport Education to Promote Social Development in Physical Education. Strategies: Advocacy in Action. 34(6).

[46] Catalano, R. F., Mazza, J. J., Harachi, T. W., Abbott, R. D., Haggerty, K. P., \& Fleming, C. B. (2003). Raising healthy children through enhancing social development in elementary school: Results after 1.5 years. Journal of School Psychology, 41(2), 143-164.

[47] Pennington, C. G. (2019). Creating and Confirming a Positive Sporting Climate. Journal of Physical Education, Recreation \& Dance. 90(4), 15-20. https://doi.org/10.1080/07303084.2019.1568936.

[48] Siedentop, D., Hastie, P. A., \& Van der Mars, H. (2011). Complete guide to sport education. Human Kinetics.

[49] Stran, M., \& Curtner-Smith, M. D. (2009). Influence of two preservice teachers' value orientations on their interpretation and delivery of sport education. Sport, Education and Society, 14(3), 339-352.

[50] Curtner-Smith, M., \& Sofo, S. (2004). Preservice teachers' conceptions of teaching within sport education and multi-activity units. Sport, Education and Society, 9(3), 347-377.

[51] Wallhead, T., \& O'sullivan, M. (2005). Sport education: Physical education for the new millennium?. Physical Education and Sport Pedagogy, 10(2), 181-210.

[52] Parker, M. B., \& Curtner-Smith, M. (2005). Health-related fitness in sport education and multi-activity teaching. Physical Education \& Sport Pedagogy, 10(1), 1-18. 
[53] McMahon, E., \& MacPhail, A. (2007). Learning to teach sport education: The experiences of a pre-service teacher. European Physical Education Review, 13(2), 229-246.

[54] Parker, M. B., \& Curtner-Smith, M. D. (2012). Sport education: a panacea for hegemonic masculinity in physical education or more of the same?. Sport, Education and Society, 17(4), 479-496.

[55] Hastie, P. A., \& Trost, S. G. (2002). Student physical activity levels during a season of sport

education. Pediatric Exercise Science, 14(1), 64-74.

[56] Curtner-Smith, M. D., Chen, W. \& Kerr, I. G. (1995). Health-related fitness in secondary school physical education: a descriptive-analytic study, Educational Studies, 21(1), 55- 66.

[57] Curtner-Smith, M. D., Kerr, I. G. \& Clapp, A. J. (1996). The impact of national curriculum physical educate on the teaching of health-related fitness: a case study in one English town, European Journal of Physical Education, 1(1), 66- 83.

[58] Curtner-Smith, M.D., Johnson, M.L., \& Vincent, J. (2003). Progressive soccer coaching: From novice to expert (2nd ed). Boston, MA: American Press.

[59] McKenzie, T. L., Sallis, J. F., \& Nader, P. R. (1991). SOFIT: System for Observing Fitness Instruction Time. Journal of Teaching in Physical Education, 11, 195-205.

[60] McKenzie, T. L. (2002). System for observing play and leisure activity in youth (SOPLAY). Retrieved August, 1 , 2006.

[61] Curtner-Smith, M. (2012). Preparing preservice physical education teachers to teach sport education. Sport education: International perspectives, 151-165.

[62] McKenzie, T. L. (2012). SOFIT (System for Observing Fitness Instruction Time): Generic Description and Procedures Manual. San Diego, CA: San Diego State University.

[63] Hastie, P. A., \& Curtner-Smith, M. D. (2006). Influence of a hybrid Sport Education-Teaching Games for Understanding unit on one teacher and his students. Physical Education \& Sport Pedagogy, 11(01), 1-27.

[64] Harvey, S., Smith, L., Fairclough, S., Savory, L., \& Kerr, C. (2015). Investigation of Students' Levels of MVPA and VPA During Physical Education Units Focused on Direct Instruction and Tactical Games Models. Physical Educator, 72, 40-58.

\section{Appendix}

\section{Modified SOFIT/SOPLAY Coding Criteria}

\section{Phase 1 - Movement Intensity}

Sedentary $=$ individual is sitting or standing in place

Walking = Individual is walking at a casual pace or is moving into or out of a ready position

Vigorous = Individual is engaged in activity more vigorous than an ordinary walking pace (e. g. stepping quickly, making a large step or lunge to reach a shuttle, moving into place while simultaneously moving into position, performing a pass or shot, moving briskly to space/defensive positioning)

\section{Phase 2 -Lesson Context}

Planned presentation

Game Play

\section{Phase 3 - On Task or Off Task Behavior}

On-task behavior = individual is participating in activity appropriately

Off-task (sedentary) behavior = individual is participating in activity inappropriately or not participating at all 